\title{
A PREDISPODIÇÄO GENÉTICA NA SÍNCOPE VASOVAGAL
}

\author{
Mariana Cristina S. Azevedo', Juarez N. Barbisan*2, Erlon Oliveira Abreu Silva ${ }^{3}$ \\ Trabalho realizado no Instituto de Cardiologia do Rio Grande do Sul - Fundação Universitária de Cardiologia, Porto Alegre, RS
}

\author{
*Correspondência: \\ Unidade de Pesquisa do IC/ \\ FUC \\ Av. Princesa Isabel, 370 \\ CEP 90620-001 - Porto \\ Alegre, RS \\ Tel: (51)32192802 Ramal \\ $22,23,24$ \\ editoracao- \\ pc@cardiologia.org.br \\ juarez.barbisan@cardiologia.org.br
}

\begin{abstract}
RESUMO
OBjetivo. Investigar uma possível predisposição genética para síncope vasovagal.

Métodos. Estudo transversal, com 252 indivíduos com história de síncope, submetidos ao teste de inclinação (TI) no Instituto de Cardiologia do Rio Grande do Sul, durante o período de setembro de 2001 a setembro de 2005. Foi analisada a relação entre história familiar positiva para síncope vasovagal e resultado do TI.

Resultados. Todos indivíduos foram submetidos ao TI sendo que 126 (50\%) casualmente tiveram resultado positivo para síncope vasovagal. História famillar dessa patologia foi identificada em 40\% (49//26 casos) dos pacientes com teste de inclinação positivo e em 25\% (3I/I26 pacientes) daqueles que tiveram TI negativo $(p=0,01)$.

ConcLusão. Há uma correlação entre a história familiar de síncope vasovagal e sua ocorrência. É possível que um componente genético possa explicar essa relação.
\end{abstract}

Unitermos: Síncope vasovagal. Hereditariedade. Predisposição genética.

\section{INTRODUÇÃO}

Síncope é caracterizada como a perda súbita da consciência, associada à incapacidade de manutenção do tônus postural, com recuperação espontânea ${ }^{1,2}$. Pode ocorrer repentinamente ou ser precedida por sintomas com duração varíável, tais como: tontura, calor, sudorese, palpitaçãa, náusea e turvação visual'. É entidade bastante comum, podendo ocorrer em 30\% da população adulta ${ }^{3,4}$. Dentre as diversas etiologias, a síncope vasovagal é a mais frequente, correspondendo a 50\% dos diagnósticos ${ }^{5.8}$.

A fisiopatologia da síncope vasovagal não é bem conhecida. Em pessoas predispostas, estímulos como dor, ansiedade e estresse podem desencadear uma resposta exacerbada do sistema nervoso autônomo. Ocorrem, então, estimulação vagal e inibição simpática com consequente bradicardia e relativa perda da vasoconstrição periférica resultando em hipotensão? A diminuição dos níveis pressóricos leva a um estado de hipoperfusão cerebral acarretando comprometimento da consciência. O diagnóstico pode ser realizado através da anamnese e exame físico; entretanto é o teste de inclinação ortostática (TI) o exame de maior acurácia, especialmente quando a etiologia é indeterminada ${ }^{10-12}$. No TI os indivíduos são colocados numa maca em decúbito dorsal horizontal por 20 minutos e posteriormente elevados em 70 graus, permanecendo nessa posição por 40 minutos. Após essa fase, denominada de passiva, é infundido nos pacientes que ainda não apresentaram síncope, I mcg de isoproterenol 15 minuto.

Alguns autores acreditam que um componente genético ${ }^{13-16}$ responsável por alterações no sistema regulador da pressão arterial, estaria presente nos pacientes comprometidos. Em estudo realizado com 227 pacientes com síncope vasovagal, 87 tinham história familiar positiva para esta entidade ${ }^{13}$. Mathias et al. encontraram forte predisposição genética para o desenvolvimento de síncope comparando parentes e amigos de pacientes com síncope vasovagal ${ }^{15}$.

Nosso trabalho tem por objetivo investigar uma possível relação entre história familiar positiva para síncope vasovagal e sua ocorrência.

\section{MÉTOdos}

Estudo transversal com 252 indivíduos, maiores de 18 anos, de ambos os sexos, com história pregressa de síncope e submetidos ao TI no Instituto de Cardiologia de Porto Alegre, durante o período de setembro de $200 \mathrm{I}$ a setembro de 2005, após assinarem termo de consentimento informado. O projeto do estudo foi aprovado pelo Comitê de Ética da instituição. Os pacientes responderam questionário referente à presença de episódios prévios de síncope, história médica pregressa, pródomos e sintomas de síncope propriamente ditos, história familiar de doenças cardíacas e síncope, e uso de medicamentos e posteriormente realizaram o TI. No TI os indivíduos são colocados numa maca em decúbito dorsal horizontal por 20 minutos e posteriormente elevados em 70 graus, permanecendo nessa posição por 40 minutos. Após essa fase, denominada de passiva, é infundido nos pacientes que ainda não apresentaram síncope, I mcg de isoproterenol por minuto.

As respostas positivas foram classificadas conforme o consenso da Sociedade Européia de Cardiologia ${ }^{10}$. Segundo essa classificação, na resposta tipo I a frequência cardíaca (FC) aumenta inicialmente e depois cai, porém não cai para valores menores que 40 batimentos por minuto

1. Médica Estagiária do Instituto de Cardiologia do Rio Grande do Sul

2. Professor pleno do Programa de Pós-Graduação em Ciências da Saúde: Cardiologia da Fundação Universitária de Cardiologia

3. Médico Residente em Cardiologista do Instituto de Cardiologia do Rio Grande do Sul 
(bpm) por menos de 10 segundos podendo ou não ter assistolia por menos de três segundos. Nesse tipo de resposta a pressão arterial aumenta inicialmente e depois cai antes da FC cair. Na resposta tipo IIA ou cardioinibitória a FC eleva-se inicialmente e depois cai para menos de $40 \mathrm{bpm}$ por mais de 10 segundos ou ocorre assistolia por pelo menos três segundos com aumento inicial da pressão e posterior queda. $\mathrm{Na}$ resposta IIB a frequência cardíaca tem o mesmo comportamento presente nas demais respostas, porém a pressão arterial cai juntamente ou após queda abrupta da FC. Já na tipo III, ou vasodepressora pura, a FC aumenta e não cai para níveis abaixo de 10\% do pico no momento da síncope e a pressão cai concomitantemente.

Os dados obtidos foram analisados pelo programa SPSS 12.0 e as variáveis submetidas ao teste de Qui quadrado e ao teste exato de Fischer.

\section{Resultados}

Dos 252 pacientes portadores de síncope submetidos ao TI, 150 $(59,5 \%)$ eram do sexo feminino. As características da amostra estão na Tabela I.

A presença de fatores precipitantes antecedendo os episódios espontâneos de síncope foi pesquisada. Tosse, deglutição, micção e ou defecação, fatores ansiogênicos, exercício físico, punção venosa, fadiga, exposição ao calor, ortostatismo prolongado, hiperventilação, refeição nas últimas duas horas ou permanência em ambiente fechado ou cheio foram os predisponentes analisados. Cento e quarenta e três pacientes (56,7\%) apresentaram algum desses fatores, sendo o mais prevalente a exposição ao calor, presente em 44 (I7,5\%) pacientes (Tabela 2).

Cento e vinte e seis (50\%) indivíduos tinham TI positivo. Aproximadamente 40\% (49//26) destes pacientes tinham história familiar positiva de síncope neurocardiogênica. Já naqueles com TI negativo foi de $25 \%$ (3I/I26 pacientes) (Figura I) .

Os pacientes apresentaram, em sua maioria, a resposta tipo I, correspondendo a aproximadamente 76,2\% (96/126) dos pacientes com TI positivo. O tipo 2A correspondeu a I I,4\% (I / / I26) dos casos. A prevalência dos demais tipos de resposta foi baixa em nossa amostra (Figura 2).

\section{Discussão}

Identificou-se que o diagnóstico de síncope vasovagal, estabelecido por anamnese, exame físico e TI positivo, associou-se fortemente com história familiar de síncope. Dos 252 pacientes, 126 tinham TI positivo, sendo que destes $40 \%$ tinham história familiar positiva, enquanto $75 \%$ dos 126 pacientes com TI negativo tinham história familiar negativa. Tais dados sugerem a existência de algum fator, possivelmente transmitido de uma geração para outra, capaz de determinar ou predispor a síncope vasovagal em parentes de pacientes com essa patologia.

Essa associação também tem sido observada por outros autores ${ }^{3-16}$. Newton et al. encontraram em seus pacientes com diagnóstico de certeza de síncope vasovagal 32,4\% de positividade na história familiar e predominância dessa relação no sexo feminino ${ }^{13}$, em concordância com nossos achados. Camfield et al., ao estudarem 30 crianças com sintomas sincopais e analisarem a história familiar dessas crianças e de seus melhores amigos, encontraram uma forte tendência familiar na ocorrência de síncope vasovagal nos pacientes e nenhuma no grupo de melhores amigos ${ }^{17}$.

\begin{tabular}{lc}
\hline \multicolumn{2}{c}{ Tabela I - Características da amostra ( $\mathbf{n}=252)$} \\
\hline Características & Resultados \\
\hline Gênero feminino $n(\%)$ & $150(59,5 \%)$ \\
Idade (anos) & $42,17 \pm 22,3 *$ \\
IMC (Kg/m²) & $24,07 \pm 4,01 *$ \\
\hline Médas 2 desvo
\end{tabular}

Médias \pm desvio padrão.

Tabela 2 - Prevalência de fatores precipitantes de síncope neurocardiogênica

\begin{tabular}{lc}
\hline Fatores & $\mathbf{n}(\%)$ \\
\hline Exposiçãa ao calor & $44(17,5 \%)$ \\
Fator ansiogênico & $42(16,7 \%)$ \\
Refeiçãa há menos de duas horas & $33(13,10 \%)$ \\
Micção & $20(7,9 \%)$ \\
Exercício físico & $16(6,3 \%)$ \\
Permanência em ambiente fechado & $16(6,35)$ \\
Ortostatismo & $14(5,6 \%)$ \\
Defecação & $6(2,4 \%)$ \\
Hiperventilaçãa & $5(2 \%)$ \\
Punção venosa & $5(2 \%)$ \\
Deglutição & $5(2 \%)$ \\
Tosse & $3(1,2 \%)$ \\
Total de pacientes & $\mathbf{2 0 9}(83 \%)$ \\
\hline
\end{tabular}

Figura I - Relação entre o resultado do TI e a história familiar dos pacientes



Figura 2 - Relação entre o número de pacientes e 0 tipo de resposta no $\mathrm{Tl}$. As respostas do TI foram classificadas segundo a classificação VASIS (10)

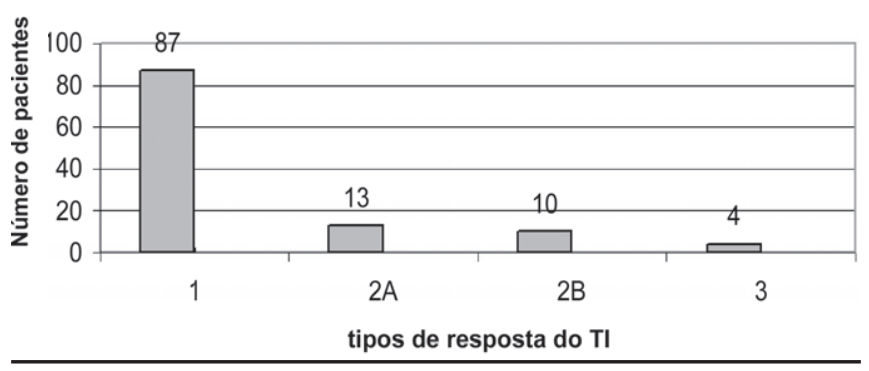


Nossos dados tiveram relevância estatística $(p=0,0$ I I), confirmando dados de outros trabalhos. Após extensa pesquisa às bases de dados internacionais (Medline, Cochrane e LiLacs), os autores não encontraram referência aos dados brasileiros previamente publicados.

A intensidade da associação observada é muito grande para ser explicada apenas por fatores ambientais comuns aos membros das famílias estudadas. Tal associação sugere que algum componente herdado possa estar implicado na fisiopatologia da síncope vasovagal. Atualmente, ainda não podemos inferir com certeza se a síncope vasovagal sofre influência de uma tendência genética ou mesmo se é proveniente de uma combinação dessas alterações com fatores ambientais aos quais esses indivíduos estariam expostos ${ }^{13}$. Através da observação de casos em parentes de primeiro grau acredita-se que mecanismos genéticos estejam envolvidos. Ainda não foram estabelecidos os genes possivelmente envolvidos na etiologia da síncope vasovagal. Alterações no gene da ECA foram recentemente estudadas como possiveis fatores causadores de síncope, porém resultados significativos que o associem ao desenvolvimento dessa patologia não foram encontrados ${ }^{18}$. Um bom começo é o estudo de genes que tenham alguma relação com os mediadores químicos do sistema nervoso autônomo. Genes candidatos à pesquisa são aqueles que originam receptores de serotonina ${ }^{19-20}$, transportadores de noradrenalina ou relacionados com a acetilcolina ${ }^{18}$.

\section{Conclusão}

Observamos que pacientes com síncope vasovagal têm, em sua maioria, parentes de primeiro grau com a mesma patologia. Concluímos, então, que possivelmente haja uma correlação entre síncope vasovagal e história familiar positiva.

São necessários estudos dos genes relacionados com os mecanismos fisiopatológicos já conhecidos dessa entidade para que se estabeleça se há realmente um componente herdável na sua etiologia. A identificação de tal gene tornaria possível intervir nos pacientes predispostos antes do desenvolvimento dos sintomas sincopais.

\section{Conflito de interesse: não há}

\section{SUMMARY}

\section{NeUROCARIOGENIC SYNCOPE AND HEREDITARITY}

OBJECTNE. To investigate a possible familial predisposition in neurocardiogenic syncope.

METHODS. Cross-sectional survey with 252 subjects, with positive familial history for syncope, who underwent head-up tilt-test (TT) at Instituto de Cardiologia do Rio Grande do Sul, between September 2001 and September 2005. The relationship between familial history for neurocardiogenic syncope and TT result was analysed.

RESULTS. Familial history for neurocardiogenic syncope was identified in $40 \%$ (49//26 cases) of subjects with positive tilt-test results and $25 \%(3 / / / 26)$ of those with negative TT.

CONCLUSION. There is a correlation between familial history for neurocardiogenic syncope and its occurence. A genetic component can possibly explain this relationship. [Rev Assoc Med Bras 2009; 55(I): 19-2I]

KEY wORDS: Syncope vasovagal. Hereditariety. Genetic predisposition.

\section{REFERÊNCIAS}

I. Freitas J, Puig J, Cunha D, Costa O, Freitas A. Síncope: Como abordar?. Rev Port Cardiol. 1994; 13:133-40.

2. Calkins H, Zipes D. Syncope and hypothension. In: Braunwald E, Zipes DP, Libby $P$, editors. $6^{\text {th }}$ ed. Heart disease: a textbook of cardiovascular medicine. Philadelphia: Saunders; 2001. p.932-40.

3. Savarage DD, Corwin L,McGee DL, Kannel WB, Wolf PA. Epidemiologic features of isolated syncope: The Framingham Study. Stroke 1985; 16:626-9.

4. Day SC. Evaluation and outcome of emergency room patients with transiet loss of consciousness. Am J Med. 1992;73:15-23

5. Castro et al.Teste de inclinação.Cardiologia Princípios Prática. 1999;20:433-7.

6. Kapoor WN, Karf M, Wiend S, Peterson JR, Levey GS. A prospective evaluation and follow-up of patients with syncope. N Engl J Med. 1983;309:197-204

7. Alquimist A, Goldenberg IF, Miltein S, Chen MY, Chen XC, Hansen R, et al. Provocation of bradycardia and hypotension by isoproterol and upright posture in patientes with unexplained syncope. N Engl J Med. | 989:320:346-5।.

8. Linzer M, Pontinem M, Gold DT, et al.Impairment of psycosocial function in recurrent syncope. J Clin Epidemiol. 1991;44:1037-43.

9. Freitas J, Puig J, Cunha D, Costa O, Freitas A. Síncope neurocardiogênica: patogenia, diagnóstico e tratamento.Rev Port Cardiol. 1996; I 5: 103-9.

I0. Mathias CJ, Bannister R. Investigation of autonomic disorders. In: Banistier R, Mathias CJ, editors. Autonomic failure :a textbook of clinical disorders of autonomic nervous system, $3^{\text {rd }}$ ed. Oxford: Oxford University Press; 1992. p.255-90

II. Sutton R, Peterson ME, Brignole M, et al. Proposed classification for tilt induced vasovagal syncope (VASIS).Eur J Cardiac Pacing Electrophysiol. 1992;3: 180-3.

12. Parry SW, Kenny RA. Tilt table testing in the diagnosis of unexplained syncope.Q J Med. 1999;92:623-9.

13. Newton J, Kenny R, Lawson J, Kenny R, Freadson R, Donaldson P. Prevalence of family history in vasovagal syncope and haemodynamic response to head up tilt in first degree relatives. Clin Auton Res. 2003; 13:22-6.

14. Mathias CJ, Deguchi K, Bleasdale-Barr K, Kimber JR. Frequency of family history in vasovagal syncope. Lancet. 1998;352:33-4.

15. Mathias C), Deguchi K, Bleasdale-Barr K, Smit S. Familial vasovagal syncope and pseudosyncope: observations in a case of a both natural and adopted siblings. Clin Auton Res. 2000; 1 0:43-5.

16. Mathias CJ, Bleasdale-Baar K, Alam M. Familial fainting- observations in three families, including one with adopted children.Clin Autonom Res. 1995;5: 105.

17. Camfield PR, Camfield CS. Syncope in childhood: a case control study of the familial tendency to faint. Can J Neurol Sci. 1990; 17:306-8.

18. Newton J, Donaldson P, Parry S, Kenny RA, Smith J, Gibson AM, et al. Angiotensin converting enzyme. Europace 2005;7:396-9.

19. Liolitsa D, Powwel JF, Prince M, Lovestone S. Association study of the 5HT-2A receptor gene polymorphism, TI02C and essencial hyperthension.J Hum Hypetens. 200 I; I 5:335-9.

20. Grubb BP, Samoil D, Kosinski D. Serotonin and syncope: An emerging connection? Eur J Cardiac Pacing Eletrophysiol 1996;5:306-14.

Aceito para publicação: 10/05/08 